\title{
Geophysical survey of earthen dam using the electrical prospecting methods
}

\author{
Yermek M. AKHMETOV ${ }^{1}$ (D), Kambar M. ASSEMOV $1, *$ (D), \\ Victor N. SHAYTOROV ${ }^{2}$ \\ ${ }^{1}$ National Center on complex processing of mineral raw materials of the Republic of \\ Kazakhstan, Almaty, Kazakhstan \\ ${ }^{2}$ Institute of Geophysical Research, Kaskelen, Almaty region, Kazakhstan
}

\begin{abstract}
The hydraulic structures for the land reclamation needs and their operation are the objects of careful attention. The water-bearing earth dams of small height pose an extra danger, where the accident occurs the most often. Such facilities should be constantly monitored to prevent the dangerous incidents. The article discusses an alternative method for studying the filtration properties of earth dams by the electrical parameters - resistivity, induced polarization and self-potential. The relative polarizability was used to exclude the influence of electrical resistivity to the induced polarization data. A study of advanced technology to identify the filter zones was carried out on an earthen dam in the Almaty region, Kazakhstan. The measurement data for three profiles are presented as the sections form in the parameters of resistivity and relative polarizability. Their complex interpretation with the respect of self-potential data, is given as a diagram of probable filtration paths. This is possibly due to the local increased watering in the dam loamy body. Then, the electric and self-potential parameters were evaluated to determine the filtering zones. The study results of above parameters have identified several water-saturated zones in the dam body. This technology could be used to estimate the condition of such objects and their engineering-geological monitoring.
\end{abstract}

Key words: earthen dam, geophysics, filtration, resistivity, polarizability, self-potential

\section{Introduction}

Many hydraulic structures in Kazakhstan were constructed in the 60-80s in the last century. The longterm operation, as well as the influence of climatic and seismic factors have gradually resulted in the moral and physical deterioration of these structures. Over the past decade, there have been more than 10 dam destructions in Kazakhstan with consequences of human

\footnotetext{
* corresponding author: Kambar M. Assemov, NC CPMRM RK, 67, Zhandossov Street, Almaty, A10M6G5, Kazakhstan, tel.: +7 727 3092560, e-mail: kassemov@kazkern.kz
} 
casualties and significant of economic, social and environmental damages (Shibutova, 2017).

Traditional methods for the structures safety determining are based on the data of external inspection and field observation. The water-physical properties data of samples taken from specially drilled wells, are used to determine the destructive processes occurring in the dam body. However, the well drilling and other excavation work violate the integrity of dam structures and may adversely affect their strength characteristics.

The world experience shows that the geophysical methods of non-destructive testing are widely used to determine the safety of hydraulic structures. The applied geophysical methods are sufficiently described in works (Camarero and Moreira, 2017; Dzhurik et al., 2014; Fatoba et al., 2018; Kayode et al., 2018; Kolesnikov et al., 2009; Kolesnikov et al., 2012; Nwokebuihe et al., 2017; Olasunkanmi et al., 2018; Prigara et al., 2012; Prigara et al., 2014; Zumr et al., 2018). An analysis of these works indicates that the seismic methods, georadar sounding and various modifications of electrometric methods are widely used. The advantage of geophysical methods is a mutual supplementation of the measured parameters of geophysical fields. Interpretation of these fields will allow the identification and prediction of adverse changes in the dam structure at the early stages.

Over the past 15-20 years, the significant positive experience of using the geophysical methods for the dams physical condition inspection has been accumulated. At the same time, the studies indicate that the solution of safety monitoring problem of hydraulic structures by geophysical methods could not be completely unified for all cases. This requires technologies, adapted to the specific physical and geological conditions, in particular, for the earth dams in Kazakhstan.

The authors have made a research to extend the set of informative parameters to improve the geophysical data reliability for the identification of filtration processes in the earth dams. The results of this work are the subject of this article.

\section{Materials and methods}

The field electrical surveys were served as an informational basis for the studying of possibility to increase the geophysical data reliability for the 
dams filtration processes identification. The induced polarization (IP) and self-potential (SP) methods were chosen for this research.

\subsection{Study Object}

The object of study was the earthen dam 18 metres high, 156 metres long and 4.5 metres wide coping in Almaty region. The dam is composed of the loamy soils. The dam body has the outlet and emergency spillway conduits. The geophysical survey scheme is shown in Fig. 1.

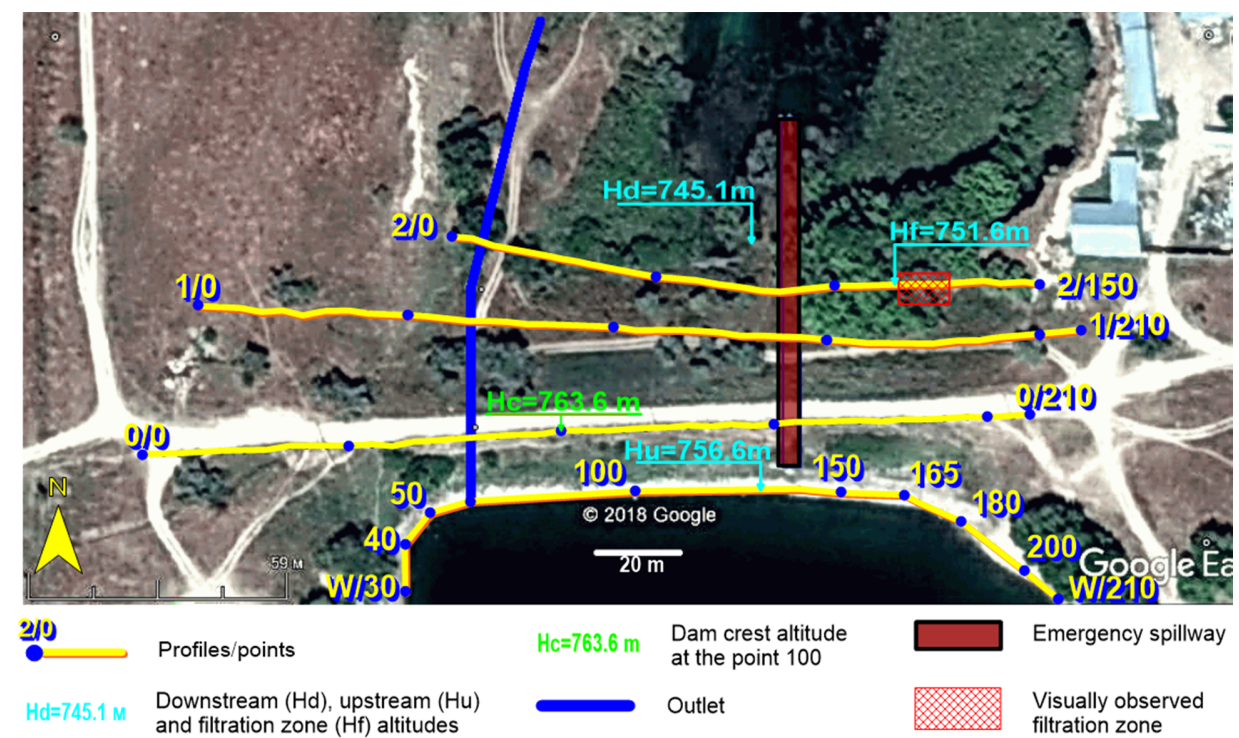

Fig. 1. The scheme of geophysical survey.

The geophysical surveys were provided with the topographic and geodetic works. They included the geophysical profiles measuring and the coordinatealtitude gridding every 5 metres in the WGS-84-UTM coordinate system.

\subsection{Metodology}

Induced polarization method (IP)

The purpose of survey was an assessment of electrical resistivity and polarizability inhomogeneity in the depth from 5 down to 40 metres of dam body 
and identification of local changes of these parameters. The regularities of resistivity decreasing and the loamy soils polarizability increasing because of moisture increasing were a physical basis for this task solving (Sharapanov et al., 1974).

The survey was performed in three profiles, laid along the coping and downstream side. The dipole electrical sounding (DES-IP) was used according to the dipole-dipole scheme (Fig. 1). The polarizability distribution data were obtained by the sounding at 8 points. In this case, the distance between the centres of supply and receiving lines had been changing (Fig. 2).

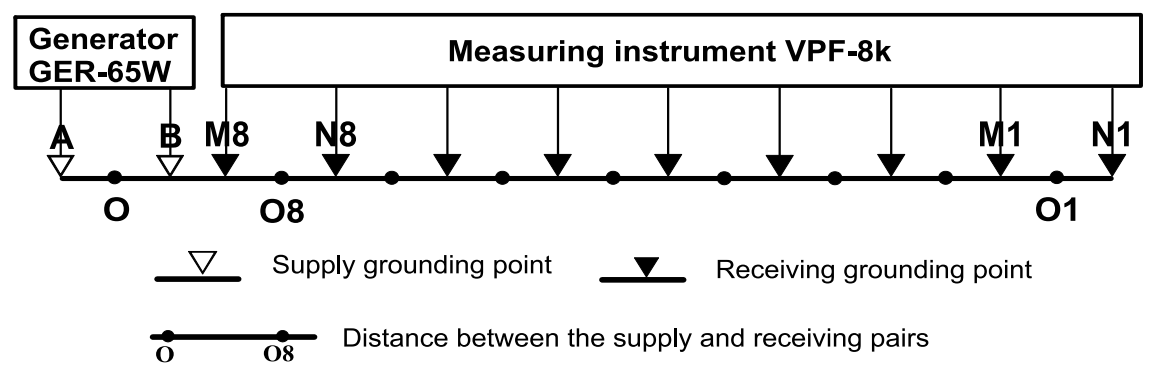

Fig. 2. The scheme of dipole electrical sounding.

The sizes of supply and receiving dipoles were 10 metres, the distance between their centers varied from 10 to 80 metres, the survey pitch - 10 metres. Such monitoring system provided the expected survey minuteness at least 40 metres depth. The used equipment: generator - GER-65W-500V, measuring instrument - VPF-8k (model of the Institute of Geophysical Research of the Republic of Kazakhstan).

It is well known that the electrical resistivity and polarizability of soils depend on the water salt content (Komarov, 1957). The parameter of relative polarizability $\left(\eta^{*}\right)$ is used to take into account this factor influence in the polarizability. It was shown in (Recommendations, 1984) that the relation $\eta^{*} \approx \eta_{a} / \rho_{a}$ is valid for the granular ion-conducting rocks, where $\eta_{a}$ - apparent polarizability and $\rho_{a}$ - apparent resistivity.

The calculations of relative polarizability show that the loams and sands stably differ with the natural moisture more than $10 \%$ (Shulga et al., 2018). In this regard, the effective IP data are presented in the form of relative polarizability graphs. 
Self-potential method (SP)

The electric field production during the fluid moving through the porous medium is the physical prerequisite for the estimation of filtration situation in the loamy dam body by the SP method (Semenov, 1980). The areas with the downward filtering are fixed by the lower potential values, and upward - by the higher values of this parameter. The intensity of observed field is higher, if the thickness of rocks is less and their resistivity is higher (Semenov, 1980). It is found that the potential increases to the water filtration direction. This is due to the fact that the boundary layer contains an excess of positively charged ions.

The SP measurements were carried out along the $\mathrm{W}$ profile line 210 metres long on headrace. The potential measurements relative to the main point in the middle of profile were carried out using the copper-sulfate non-polarizable electrodes according to the requirements (Engineering surveys for construction, 1987). A measuring device was the VPF-210 electric prospecting receiver (model of the Institute of Geophysical Research of the Republic of Kazakhstan).

The SP data processing includes the construction of potential increment graph along the profile and its interpretation. The results of repeated measurements show the error within $\pm 5 \%$, which corresponds to the requirements (Engineering surveys for construction, 1987). The patterns of SP changes associated with the filtering processes were also analysed.

\section{Results and discussions}

The data processing included the drawing of sections $\rho_{a}$ and $\eta^{*}$ for all measurement points. These sections provide the spatial change of polarizability and resistivity as well as the presence of local changes of these parameters.

The interpretation results of DES-IP and SP measurements are shown in Figs. 3 and 4.

\section{Vertical section of resistivity}

Fig. 3 shows that the dam vertical section is characterized by the low $\rho_{a}$ not more than $30 \Omega \mathrm{m}$ in all three sections. The specified parameter increases with the depth rise. 


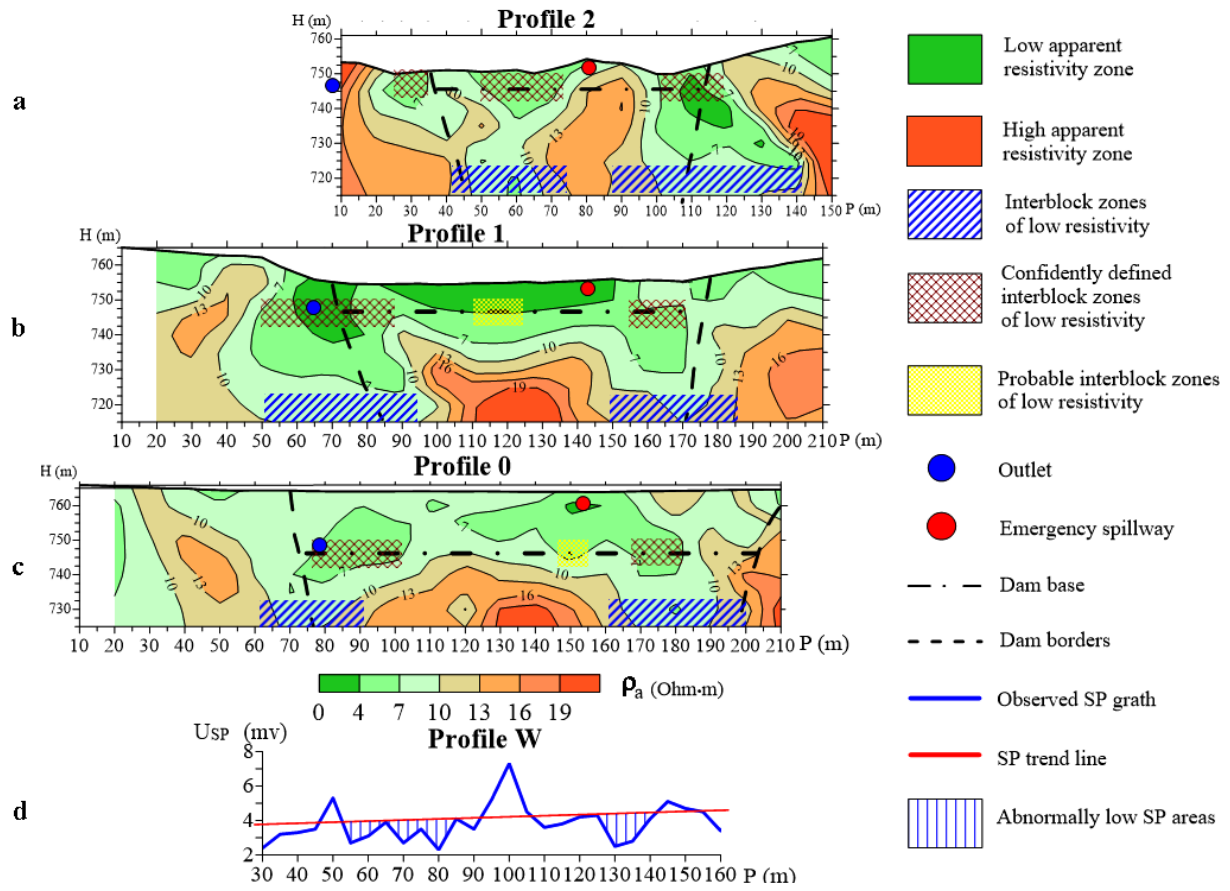

Fig. 3. The map of resistivity contours (a), (b), (c), self-potential graph (d).

A characteristic feature of $\rho_{a}$ sections is the significant lateral irregularity. The electrically conductive areas of various sizes and contrasts are observed. They determine the block structure of dam body sections.

There are the electrically conductive areas at the dam sides along three profiles (profile 0 points $60-95$ and $160-195$, profile 1 points $47-90$ and 150 175, profile 2 points $35-62$ and 100-133). These areas are shown over the entire range of sounding depths from 5 to 40 metres down, including below the dam base and in the visually observed water filtration zone around the points 110-125 along profile 2 .

There are the metal structures in the dam body - the reservoir outlet and emergency spillway, which affect the resistivity distribution. This effect shows itself in the form of local increased electrical conductivity anomalies and the ambiguous interpretation of vertical sections around conduits. The increased electrical conductivity areas extend much lower than the conduit location (profiles 0 and 1 ), or do not correlate with these objects position 


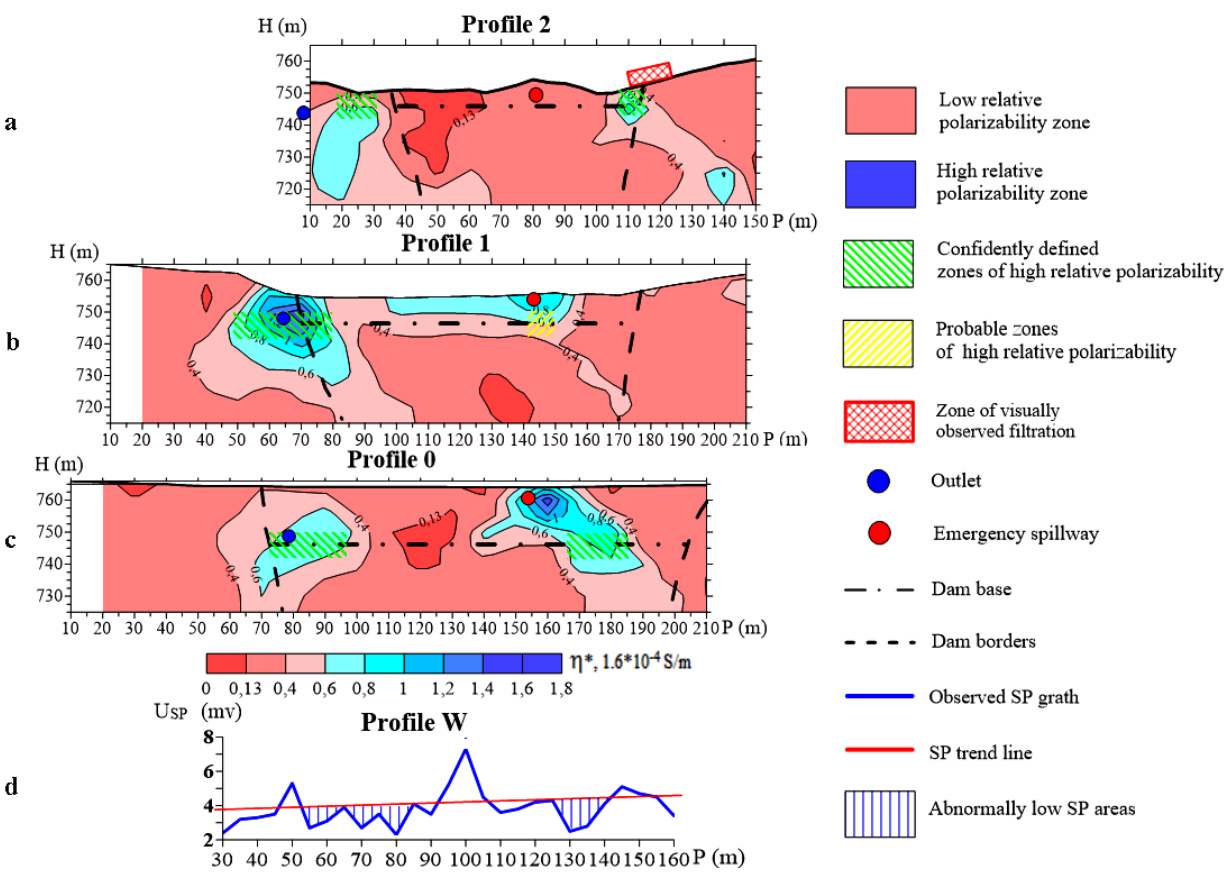

Fig. 4. The map of relative polarizability contours (a), (b), (c), self-potential graph (d).

(profile 2). It is very likely that the observed electrical conductivity effects could be interpreted as the consequence of changing of geological engineering conditions, the local increasing of moisture content in the dam loamy body.

Such local increased moisture is quite possible due to the jet water filtering. The SP data along the $\mathrm{W}$ profile indirectly confirm this supposition. Two zones with lower SP were found near points 55-85 and 125-143 along this profile. It is typical for the downward water filtering (Shulga et al., 2018). According to the DES data they are located almost in the range of increased electrical conductivity areas.

\section{Vertical section of relative polarizability}

The distribution of relative polarizability and its interpretation are presented in Fig. 4. The main pattern of this parameter distribution is its background or lower values in the central parts of sections. The most contrasting increased polarizability areas are on the flanks. 
The maximized polarizability areas also have the shallow depth along profile 1, where the outlet and spillway are close to the surface. Such spatial relationship between the polarizability anomalies and pipelines in the increased soil moisture zones gives the good reason to suppose that these anomalies have the redox nature.

The distribution of resistivity and relative polarizability parameters is shown in Fig. 5.

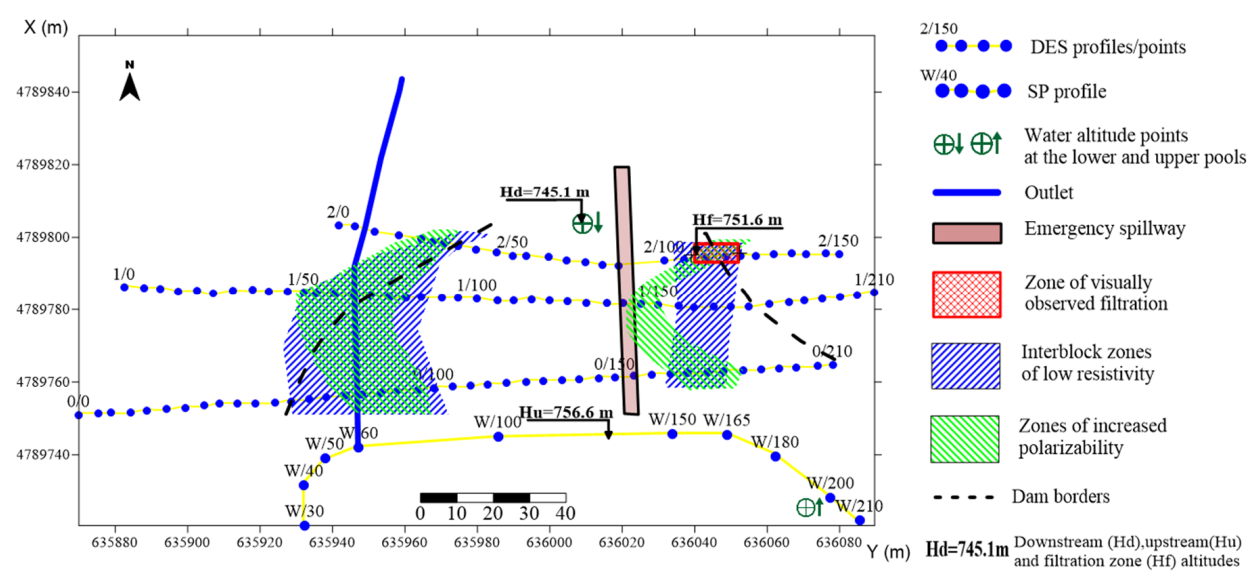

Fig. 5. The scheme of possible filtering zones according to the DES-IP data.

The abnormally increased polarizability areas are mainly consistent to the increased electroconductivity zones, except the sections of profile 1 points $140-155$ and profile 2 points $20-30$. The anomalous polarizability zones for these intervals are more common at the western periphery of electro-conductive zones. The detailed surveys of these areas are needed to establish the reasons for this discrepancy.

In total, the results of DES-IP are evidenced about the high efficiency of this method for the heterogeneity studying of dam body and identifying the increased water permeability areas. These areas can be the ways of concentrated water filtration from the reservoir under "the favourable conditions".

\section{Conclusion}

As a result of geophysical studies, the following conclusions are made: 
- The DES-IP data quite well distinguish the heterogeneous structure of dam body. This heterogeneity of electric parameters possibly is associated with the presence of increased water-cut zones. Based on these data, it becomes possible to chart the potential filtering paths.

- The studies have shown the relevance to clarify the electric anomalies nature in the areas of possible water pipelines influence. The solution to this task requires to use the methods, aimed to obtain the information about the loamy soils elastic-deformation properties. It is these properties primarily change with the increasing of local water permeability.

It is necessary to conduct the regime self-potential observations at the different reservoir fullness for more reasonable identification of filtration zones. This will eliminate the influence of redox and adsorption-diffusion potentials from the metal structures and clay - sand sediments.

Acknowledgements. The research was funded within the project No. AP0513 4944 "The development of methods for monitoring of hydraulic facilities stability based on the complex engineering and geophysical studies", granted by the Ministry of Education and Science of the Republic of Kazakhstan. The authors declare no conflict of interest.

\section{References}

Camarero P. L., Moreira C. A., 2017: Geophysical investigation of earth dam using the electrical tomography resistivity technique. REM, Int. Eng. J., 70, 1, 47-52, doi : 10.1590/0370-44672016700099.

Dzhurik V. I., Eskin A.Yu., Serebrennikov S. P., Bryzhak E. V., 2014: Physical condition dynamics on the weakened zones of the bulk dam of the Irkutsk Hydroelectric Power Station for the period 2002-2012. The Bulletin of Irkutsk State University - Series: Earth Sciences (Izvestiya Irkutskogo Gosudarstvennogo Universiteta - Seriya: Nauki o Zemle), 8, 35-41, available at: http://izvestiageo.isu.ru/ru/article/file? id=217 (in Russian with English summary).

Engineering surveys for construction, 1987: Technical requirements for the production of geophysical works. Electrical intelligence. Gosstroy of the RSFSR (Republican building norms 64-87), available at: http://www.snip-info.ru/Rsn_64-87.htm (in Russian).

Fatoba J. O., Eluwole A. B., Ademilua O. L., Sanuade O. A., 2018: Evaluation of subsurface conditions by geophysical methods at Ureje Earth Dam Embankment, AdoEkiti, Southwestern Nigeria - A case study. Indian J. Geosci., 72, 4, 275-282, available at: https://bit.ly/3hlBbdX.

Kayode O. T., Odukoya A. M., Adagunodo T. A., Adeniji A. A., 2018: Monitoring of seepages around dams using geophysical methods: a brief review. IOP Conf. Ser.: 
Earth Environ. Sci., 173, 2nd International Conference on Science and Sustainable Development, 493-499, doi : 10.1088/1755-1315/173/1/012026.

Kolesnikov V. P., Konoplev A. V., Prigara A. M., Tatarkin A. V., 2012: Technology of complex engineering-geophysical surveys for diagnosing the state of hydraulic structures. Sovremennye problemy nauki i obrazovaniya, 6, available at: https://www.science-education.ru/ru/article/view?id=7839 (in Russian with English summary).

Kolesnikov V. P., Tatarkin A. V., Prigara A. M., Konoplev A. V., 2009: Status diagnosis of earth dams by non-destructive testing methods. Geology and Minerals of the Western Urals: Materials of regional scientific and practical conference, Perm University, Perm, 257-262.

Komarov V. A., 1957: On the nature of electric fields caused by polarization and the possibilities of their use in the search for ore deposits. Vestnik gosudarstvennogo universiteta: Seriya Geologiya and Geographiya, 16, 37-46.

Nwokebuihe S. C., Alotaibi A. M., Elkrry A., Torgashov E. V., Anderson N. L., 2017: Dam Seepage Investigation of an Earthfill Dam in Warren County, Missouri Using Geophysical Methods. AIMS Geosciences, 3, 1, 1-13, doi: 10.3934/geosci.2017.1.1.

Olasunkanmi N. K., Aina A., Olatunji S., Bawalla M., 2018: Seepage Investigation on an Existing Dam using Integrated Geophysical Methods, J. Environ. Earth Sci., 8, 5, 6-16, available at: https://iiste.org/Journals/index.php/JEES/article/down load/42360/43627.

Prigara A. M., Tatarkin A. V., Pensky A. V., Osovetsky B. M., Konoplev A. V., 2012: Determination of physical and mechanical properties of soils when assessing the condition of hydraulic structures using non-destructive testing methods. Nauchnyi zhurnal KubGAU, 84, 10, available at: http://ej.kubagro.ru/2012/10/pdf/13.pdf (in Russian).

Prigara A. M., Tsarev R. I., Konoplev A. V., Pensky O. G., Osovetsky B. M., 2014: Engineering and geological assessment of hydraulic structures with non-destructive testing methods. Fundamentalnye issledovaniya, 11, 2, 348-352, available at: https:// www.fundamental-research.ru/pdf/2014/11-2/35525.pdf (in Russian with English summary).

Recommendations on the methodology for predicting changes in the construction properties of structurally unstable soils during flooding. Industrial and Research Institute for Engineering Surveys in Construction, Stroiizdat, Moscow, 1984, 156 p. (in Russian).

Semenov A. S., 1980: Electrical exploration using the natural electric field method. Publisher Nedra, Leningrad, 446 p., available at: http://geo.web.ru/db/msg.html?mid $=1183685$ (in Russian).

Sharapanov N. N., Chernyak G. Ya., Baron V. A., 1974: The methodology of geophysical research in hydrogeological surveys with the aim of land reclamation. Publisher Nedra, Moscow, 176 p., (in Russian).

Shibutova L., 2017: The issue of flood prevention in Kazakhstan: statistics of destructions. Information Agency Regnum, available at: https://regnum.ru/news/economy/227 9631.html/ (in Russian). 
Shulga M. V., Zholdybayev A. K., Kusherbayev N. N., 2018: Electrical survey during the assessment of the dynamics of subsoil inundation in nuclear energy facilities locations (at the example of VVR-K INP). Vestnik Nacionalnogo Yadernogo Centra, 3, 75, 6772, available at: https://www.nnc.kz/media/bulletin/files/NOp9IwYoNM.pdf.

Zumr D., David V., Krása J., Nedvěd J., 2018: Geophysical Evaluation of the Inner Structure of a Historical Earth-Filled Dam. Proceedings (MDPI), 2, 11, 664, 1-7, doi : $10.3390 /$ proceedings 2110664 . 